\title{
La relación del alimento dentro de la historiografía conventual novohispana
}

\author{
Yolanda García González* \\ Centro de Enseñanza para Extranjeros
}

\begin{abstract}
Resumen: La historia de la alimentación es un tema que puede abordarse desde diferentes perspectivas y a través de diversas fuentes. La culinaria conventual se ha convertido en un referente de interés debido a la gama de posibilidades de estudio que brinda la información contenida en los documentos monacales. Este artículo pretende mostrar cómo se ha estudiado el tema de la alimentación conventual a partir de una serie de documentos ligados directa o indirectamente a lo culinario.
\end{abstract}

Palabras clave: alimentación, dieta conventual, conventos femeninos.

Abstract: The culinary history is a topic that could be seen from different perspective and through various sources.

The convent consumption has become a benchmark interest because of the range of study opportunities offered by the information contained in the monastic documents.

This article aims to show how the conventual consumption has been studied from a series of documents related directly and inderectly to the culinary.

Keywords: culinary, conventual consumption, nunneries.

El consumo de alimentos es un proceso que se desarrolla cotidianamente pero la forma en que nos alimentamos puede rebasar este límite para convertirse en un símbolo de estatus, en la entrega de nuestro cuerpo y de nuestra alma a un ser superior, o a un arte basado en la imaginación y la experimentación. Estos tres aspectos son un claro ejemplo de la comida conventual novohispana, una de las prácticas más satisfactoria de la vida cotidiana.

* Doctora en Historia por la Facultad de Filosofía y Letras de la UNAM, enfocada en la investigación sobre prácticas alimentarias en la Ciudad de México. 
Desde que dio inicio el siglo $\mathrm{XXI}$, se ha presentado un mayor número de publicaciones ligadas al tema de la cocina; tanto investigaciones especializadas como obras de divulgación cuyo objetivo es mostrar un panorama más amplio sobre la alimentación en los conventos durante la época novohispana.

Este interés ha sido el punto de partida para la presente revisión, la cual está enfocada en mostrar las diversas facetas que ofrecen estas obras y con ello realizar un balance crítico sobre sus aportaciones o sobre la limitación que ofrezcan, así como reconocer qué fuentes y documentos se han estudiado para ir forjando una perspectiva y una forma de análisis propia.

Pero, ¿por qué realizar una revisión historiográfica sobre la comida conventual novohispana? Para mí, la comida y todo lo que la rodea es una forma de aproximarnos a los gustos y las costumbres de una sociedad. El estudio sobre los hábitos alimentarios de un grupo nos permite reconocer las necesidades en un tiempo y un espacio determinados. Las características que cubrieron la alimentación conventual femenina son una muestra de las continuidades y las rupturas que se han presentado a través de la historia y, en este caso, son reflejo de la cotidianeidad novohispana.

Para acercarse a estos ricos temas están las obras que han permitido el estudio de la culinaria conventual de una manera indirecta, por ejemplo los trabajos que se ligan a la reconstrucción histórica de las edificaciones conventuales pues dan pie a otras investigaciones dentro del ámbito de lo cotidiano, como el análisis de la dieta.

Considerando las distintas posibilidades de análisis sobre el tema de la alimentación, a continuación presento la revisión de textos que aportan un acercamiento al amplio panorama de la culinaria monacal. El esquema de trabajo que presento como una forma de divulgación de la culinaria conventual está compuesto por tres apartados que, de manera directa o indirecta, hacen una relación al mundo culinario de los conventos novohispanos: obras generales de historia conventual, trabajos de divulgación y por último, investigaciones especializadas en el ámbito de la alimentación monacal.

\section{HistoRIOGRAFÍA CONVENTUAL}

Una de las obras pioneras que ha marcado la historiografía conventual es Conventos de monjas en la Nueva España (Muriel, 1946). El objetivo principal de esta obra es aproximarnos al origen de las órdenes religiosas femeninas en la Nueva España y un acercarnos a la vida cotidiana dentro de estos espacios. Por desgracia, debido a la falta de materiales, fuentes e investigaciones acerca del tema en la época en que fue presentado este trabajo tuvo como consecuencia una serie de vacíos en el relato de las fundaciones y las actividades monjiles. 
Siguiendo el rastro de la influencia de los conventos femeninos se encuentra Cultura femenina novohispana (Muriel, 1982), enfocado en la revisión y el análisis del papel de la mujer dentro de la sociedad novohispana, a través de casos sobresalientes en la vida tanto conventual como laica de la época colonial, hecho que ayuda a replantear la importancia del papel de la mujer en la historia.

En las dos publicaciones es posible encontrar apartados referentes a la culinaria conventual, la cual es descrita por la propia autora como "una de las actividades que con mayor agrado realizaban las monjas en su tiempo libre", es decir, al momento de terminar con los quehaceres diarios del convento y tras finalizar sus oraciones, marcadas por las respectivas Reglas y Constituciones (Muriel, 1982: 475). Con este referente se puede reconocer cómo la culinaria fue una forma de expresión y de creatividad; una motivación para la población dentro de los conventos.

Gracias a este interés en la cocina, Josefina Muriel nos proporciona algunos ejemplos sobre los alimentos que se elaboraron en los conventos de la Ciudad de México como: los alfeñiques y los caramelos preparados en San Jerónimo y San Lorenzo, dos de los conventos, según Muriel, más famosos por su dulcería; las empanadas de la Concepción y San Bernardo, y los guisos de pescado adobado que elaboraban las carmelitas (Muriel, 1982: 477).

Otro de los trabajos que ha llegado a ser un referente importante para la realización de investigaciones sobre el ámbito conventual es Conventos de monjas: fundaciones en el México virreinal, (Amerlinck, 1995), el cual brinda un panorama sobre las fundaciones conventuales a lo largo del territorio de la Nueva España durante los siglos XVI al XVIII, así como la desamortización de los mismos a mitad del siglo XIX.

A diferencia de la historiografía decimonónica que presentaba estos espacios como lugares sin sentido, donde las mujeres se pasaban el tiempo encerradas realizando quehaceres y rezando a lo largo del día, las investigaciones actuales han mostrado que estos espacios se organizaban de una manera similar al mundo exterior, por lo que "los conventos femeninos constituyeron una presencia viva en la sociedad colonial" (Amerlinck, 1995: 19).

El trabajo muestra que las mujeres consideraban válida la idea de optar por la vida religiosa, ya que, en muchas ocasiones, constituyó un acto de libertad (Amerlinck, 1995: 23) Esta libertad se puede ver reflejada en las diferentes actividades que se realizaban dentro de los monasterios. Si bien, las monjas se comprometían a seguir los votos de clausura, muchas veces confundido con el abandono del mundo terrenal por el espiritual, no podían dejar de lado las actividades que permitieran el correcto funcionamiento del convento; entre ellas, fueron capaces de reflejar a través del arte, la música o la cocina, sus propias necesidades. 
Así pues, se debe tomar en cuenta el gran aporte de esta obra, principalmente porque nos muestra cómo a través de las bulas y libros de fundación se pueden recrear aspectos de lo cotidiano a través de la historia arquitectónica novohispana.

Otro ámbito que permite reinterpretar la vida conventual y el ámbito de lo culinario es la cuestión económica, fundamental para el funcionamiento del convento en sí mismo y en relación con la sociedad. Uno de estos ejemplos es Los conventos femeninos y el mundo urbano de la Puebla de los Ángeles del siglo XVIII (Loreto, 2000) donde se estudia la relación entre los conventos y la ciudad, analizando el papel de estos centros como punto clave en la relación con la religiosidad, la ciudad, la familia y el individuo durante la época novohispana.

El análisis planteado por Loreto incluye el aspecto de la alimentación como reflejo del consumo, la penitencia y la purificación en la concepción de las imágenes monjiles. A partir de la revisión de las Reglas y las Constituciones de las órdenes religiosas, la autora se acercó al análisis de las dietas, en su mayoría muy estrictas, ya que la ingesta suponía la búsqueda de perfección y salvación, una de las entregas más grandes que las monjas podían ofrecer a Dios. (Loreto, 2000: 293).

Un caso que retoma Loreto es el de las monjas dominicas, quienes, según su Regla, debían permanecer en ayuno de carne roja durante siete meses, además de los días viernes y sábados, durante las fiestas marcadas por su Constitución, y ciertos días que la Priora decidía establecer fuera de los marcados por la Iglesia (Loreto, 2000: 152).

Según han expresado varios investigadores, estos ayunos fueron, muy probablemente, la causa de que las monjas hayan experimentado las visiones místicas que las ponía en contacto directo con Dios tal cual lo muestra Deyanira García en "El accidente de epilepsia en el convento de religiosas del glorioso y máximo doctor señor san Jerónimo en la Puebla de los Ángeles" (García, 2007). Gracias a este análisis se puede ver que la alimentación fue un aspecto central en la vida de los conventos, controlado tanto por las Reglas de la orden, como por las propias normas que imponían sus habitantes, en este caso, la priora, así como las prácticas que cada una de las monjas pudiera efectuar con la intención de lograr su encuentro con el Señor.

De manera más reciente, Las esposas de Cristo. La vida conventual en la Nueva España (Lavrín, 2016) describe las actividades culinarias de diversos conventos a lo largo del siglo XVII, tanto del día a día, como de las preparaciones que las monjas realizaban a lo largo del año para algún festejo importante para la ciudad. Un ejemplo que trata la autora es el paseo del pendón, una celebración que cada 13 de agosto se llevaba a cabo para rendir obediencia al rey. Para la fiesta se aportaban especialidades como pastillas de boca o caramelos macizos perfumados, fruta horneada, orejones y hojaldrados entre varios más (Lavrín, 2016: 207). 
Esta información permite ver cómo la comida, especialmente la elaboración de confites por parte de las religiosas, funcionó como un aporte económico que, según los libros de gastos, la mayoría de las veces, era empleado en los arreglos de las iglesias o la hechura de mejoras en las celdas de las monjas.

Desde la perspectiva de la economía también es posible encontrar referencias sobre el tema de la alimentación está El convento de San Jerónimo: vida conventual y finanzas (Reyna, 1990), cuya propuesta principal es mostrar el papel de este convento como fuente de crédito e institución financiera y arrendadora para la sociedad novohispana, sin dejar de lado aspectos de la vida conventual cotidiana.

Para su desarrollo, la autora se basó en un corpus de documentos localizados en el Archivo General de la Nación dentro de los ramos de Bienes Nacionales y Clero regular y secular. El primero de ellos es de 1604 y trata el caso de una negra habitante del convento de San Jerónimo, y culmina con el testimonio del mayordomo Manuel Álvarez de la Cadena, fechado en 1859 (Reyna, 1990: 7-8).

El hecho de recurrir a diversos documentos relacionados con la vida dentro y fuera del convento de San Jerónimo, brinda la posibilidad de llevar a cabo nuevas interpretaciones sobre la vida monacal y el papel que los conventos de monjas jugaban en la sociedad colonial. Gracias a este estudio podemos ver que el convento contaba con una organización similar a la del mundo exterior. Por este motivo, las religiosas debían ocupar oficios y actividades ligadas a la correcta estructura que las regía.

Según sus capacidades, las monjas debían cubrir los puestos de: priora, vicaria, provisora, contadora, portera, tornera, refitolera, maestra de mozas y maestra de jóvenes, enfermeras, entre otras (Reyna, 1990: 23).

Con relación a los hábitos alimentarios en San Jerónimo, Reyna incluye un auto de la visita que fray Payo de Rivera hizo al convento en 1673. Esta visita estipuló el tipo de dieta que debía seguir la comunidad: las españolas y las criollas podían consumir 24 onzas de pan blanco y dos libras de carnero, a diferencia de las criadas, a quienes se les destinaban cuatro reales de pan o semita y 10 libras de vaca (Reyna, 1990: 28). Gracias a esta referencia es posible observar cómo la comida fue un factor que marcó el rango entre las habitantes del convento; si bien, se vive en comunidad, no debía existir similitud en los privilegios que se recibían, cada sector fue bien identificado a través de su dieta.

También se determinó que el mayordomo y el administrador del convento otorgarían a la provisora 160 pesos para la compra de pescado y semillas; la priora recibiría cada mes dos pesos para frijoles y la procuradora 30 pesos para los gastos de enfermería, refectorio, compra de aves y dulces para los enfermos, y a la semana se otorgarían cinco pesos para la compra de leña y ocho para los gastos de cocina (Reyna, 1990: 29). 
Esta información es clave para reconocer las prácticas relacionadas con la alimentación: los privilegios para cada uno de los grupos que ocupaban el espacio, el tipo de productos que se ingería, las cantidades y costos de cada alimento, así como los gastos para productos especiales, como la dieta de los enfermos.

Para ampliar esta información, se encuentra el libro de Autos de las visitas del arzobispo fray Payo Enríquez a los conventos de monjas de la ciudad de México (1672-1675), (Pérez, 2005) en el cual, Leticia Pérez muestra los conflictos que se originaron tras las visitas que el Arzobispo realizó a nueve conventos de monjas sujetos a su jurisdicción.

La información recabada permite observar cómo se reguló la distribución de los alimentos, los gastos y los salarios en el convento de Nuestra Señora de la Limpia Concepción; en Regina Coeli se enlista la compra de pan y carnero, así como los gastos ordinarios y extraordinarios; también es posible conocer la reforma de los gastos comunes del convento de Nuestra Señora de la Encarnación, y la minuta de gastos del convento de Santa Inés.

El que estos documentos se hayan incluido para comprender el contexto que se vivía a mediados del siglo XVII, enriquece el panorama sobre el papel que jugó la alimentación, específicamente, dentro del ámbito conventual. Las fuentes señaladas permiten ver cómo las prácticas alimentarias formaron parte de las reformas que se impusieron para regular la vida en comunidad con el fin de que las monjas no corrompieran sus votos de clausura y pobreza, dejando abierta la línea de investigación para estudiar cómo estaba conformada la dieta conventual en la práctica cotidiana.

Como puede verse, los trabajos relacionados con la historia económica y la relación de las fundaciones de los conventos novohispanos incluyen referencias significativas sobre el tema de la alimentación. La historiografía conventual permite ver cómo la revisión y el análisis de los autos de visita o las Reglas y las Constituciones de las órdenes religiosas pueden ampliar el estudio de la cocina conventual.

Trabajar a través de diversos aspectos no relacionados directamente con la comida hace posible la reinterpretación de las prácticas y de los hábitos alimentarios en un grupo determinado, lo que ha permitido tener un panorama más amplio sobre la alimentación novohispana.

\section{TRABAJOS DE DIVULGACIÓN}

A partir de los años noventa del siglo pasado comenzó un notable interés por el rescate de la culinaria mexicana, hecho que ha brindado una gran variedad de trabajos especializados en el tema y donde, sin lugar a dudas, han figurado las investigaciones relacionadas con las creaciones conventuales de la Nueva España. 
Gracias a las obras de divulgación, pioneras en el tema, se comenzó a generar una producción sobre contextos y recetarios que abarcan la cocina mexicana, lo que ha traído consigo la iniciativa por realizar investigaciones más especializadas.

Como parte del rescate de la historia de la cocina novohispana, figura el papel que realizó Guadalupe Pérez San Vicente, gran apasionada del tema de la culinaria mexicana. Debido a su estrecho vínculo con el Archivo General de la Nación pudo entrar en contacto con diversos recetarios y libros de cocina inéditos de finales del periodo colonial, pues de manera fortuita, como ella misma lo expresa, trabajó, junto con Josefina Muriel, uno de los documentos más sobresalientes de cocina conventual: el recetario del convento de San Jerónimo, seleccionado y trascrito por Sor Juana Inés de la Cruz (Muriel, Pérez San Vicente, 1996).

Por su parte, Teresa Castelló Yturbide trabajo el documento que dio forma al Libro de cocina del hermano fray Gerónimo de San Pelayo, recetario franciscano del siglo XVIII que incluye preparaciones y prácticas relacionadas con los alimentos, que debían cumplirse por la comunidad, y Delicias de antaño: historia y recetas de los conventos mexicanos, (Castelló, 2000) obra que recupera alrededor de 80 especialidades representativas de diversos conventos como las puchas, panes dulces en forma de rosquilla, del convento de Santa Rosa, los buñuelos de Santa Brígida, o los camotes de Santa Clara.

A finales del siglo XX, la editorial Clío publicó la serie Cocina virreinal novohispana, enfocada, principalmente, a la cocina en los conventos. En esta serie participaron autores como la ya citada Rosalva Loreto, Mónica Lavín y Yuri de Gortari quienes junto con Edmundo Escamilla y Ana Benítez Muro recrearon la historia y las recetas de la época colonial.

Este fue un esfuerzo por dar a conocer la historia de la comida mexicana de una forma más atractiva, a través del uso de imágenes, datos de interés, así como de recetarios especializados en las delicias conventuales. La variedad en la producción de trabajos de divulgación es un elemento que debe considerarse, ya que se trata de un parteaguas en el estudio especializado de la alimentación en nuestro país. Sin estos primeros esfuerzos, el tema de la culinaria no tendría el auge que lo caracteriza en nuestra actualidad.

Los esfuerzos por dar a conocer el tema han motivado a una serie de antropólogos e historiadores, entre los que me incluyo, a investigar con mayor profundidad la importancia de la ingesta de alimentos dentro de las comunidades monjiles, así como su relación con la sociedad urbana.

Como consecuencia, a partir de los últimos años han aparecido un mayor número de investigaciones que muestran, desde diversas perspectivas y fuentes, el papel de la comida dentro de los conventos novohispanos con el 
objetivo de reconocer las prácticas alimentarias en las cuales se puede incluir el tipo de alimentos, la forma de prepararlos, su origen y costos, entre otros elementos que permiten reconocer los rasgos de una sociedad.

\section{LOS TRABAJOS ESPECIALIZADOS}

El interés por recrear la cocina conventual novohispana ha dado pie a la búsqueda y la reinterpretación de diversos documentos que nos acerquen a este contexto. Uno de los contratiempos principales es la carencia de fuentes directas que se ligan a este tema como serían los recetarios o los libros de cocina; sin embargo, este hecho ha abierto el camino a la revisión de otras referencias cercanas al ámbito alimentario.

Los libros de cuentas o cuadernos de gastos, así como las Reglas y las Constituciones de las órdenes religiosas, han marcado el punto de partida de las nuevas investigaciones. Gracias a este tipo de fuentes, es posible conocer un tipo de dieta conventual de principios del siglo XVII en la ciudad de México que claramente muestra un temprano mestizaje entre el Viejo y el Nuevo Mundo.

Como referencia de este interés se encuentra Los místicos sabores del convento (Arias, 2007), un estudio que aborda las prácticas adquiridas por las monjas clarisas urbanistas de Querétaro durante los siglos XVII y XVIII. La relación entre el convento y la sociedad queretana durante este periodo, marca el tipo de alimentos que se consumían en el convento. El aporte que ofrece este trabajo es el poder ubicar las diferencias regionales en las prácticas alimentarias a lo largo del territorio novohispano; en este caso en particular, se pueden reconocer las peculiaridades de la región queretana, donde alimentos como el guamiche, una cactácea originaria de la zona, forma parte de las preparaciones culinarias de la orden (Arias, 2007: 80).

Al igual que otros autores, Arias se basa en las Reglas y las Constituciones de las clarisas urbanistas para conocer más sobre la dieta que debía seguir la comunidad. Uno de los aportes que brinda este estudio es el análisis comparativo de las costumbres culinarias entre la alimentación del siglo XVIII y las prácticas que sigue realizando la comunidad del convento en la actualidad, lo que muestra la continuidad de las tradiciones que se gestaron desde los primeros años del convento.

Alicia Bazarte, en Un acercamiento a la comida novohispana (Bazarte, 2006), utilizó un cuaderno de gastos del convento de San Lorenzo de la ciudad de México que muestra el registro de alimentos datado entre el 21 de marzo y el 8 de julio de 1628. Entre los productos enlistados figuran frutas, verduras, chiles, carne y huevos, entre otros. Junto con este registro, Bazarte presenta 
un documento que hace referencia a la compra de harina que se hizo en una temporalidad que abarcó del 2 de octubre de 1624 al 8 de julio de 1628, dentro del mismo convento.

Una de las peculiaridades es que se menciona el nombre de los proveedores, lo que permite realizar un estudio de redes y conocer el impacto social y económico que el convento de San Lorenzo representaba para la ciudad de México. Ambas aportaciones nos permiten abundar en el tema de la alimentación pero también es posible considerar el aspecto económico y las relaciones sociales y culturales que surgen a partir de la red de intercambios entre la comunidad conventual y el mundo exterior.

El detalle de las prácticas alimentarias se amplía con Ingredientes para la cocina conventual: producción y compras en dos estudios de caso (Salazar, 2014). Aquí, nuevamente los cuadernos de gasto ocupan un papel principal, pues han resultado clave para reconocer las diversas dietas conventuales, que, como se ha mencionado con anterioridad, puede responder a lo estipulado en las Reglas y las Constituciones de cada orden, pero también a la variedad de productos autóctonos de cada zona.

El artículo de Nuria Salazar se centra en el estudio de caso de dos conventos novohispanos: Jesús María en la Ciudad de México y el de Nuestra Madre Santa Clara de la Villa de Carrión, ubicado en Atlixco. Las particularidades de cada uno de ellos, permite acercarse a la práctica de la autoproducción dentro de las huertas y de los pequeños corrales que se instalaban en la mayoría de las instituciones.

Además de tocar la conformación de los espacios, este análisis muestra el organigrama de los responsables de la entrada, la compra y la producción de los alimentos dentro de los conventos. Entre los personajes principales figuraban: la priora, quien destinaba parte de las dotes al gasto de cocina y junto con ella trabajaba la provisora mayor, la panadera, la repostera, la colacionera y la refitolera, encargada del refectorio o comedor de la comunidad (Salazar, 2014: 75).

La visión de un espacio bien organizado no sólo se ve reflejado en el personal encargado sino en la variedad de los alimentos que debían consumirse, ya fuera en la dieta cotidiana, de celebraciones, de ayunos y de comidas de las enfermas. La mención que se hacía sobre la abstención de carnes rojas y productos lácteos varía; para las clarisas se estipula que no debían consumir carnes, excepto las monjas enfermas y algunas excusadas por permiso explícito de la priora (Salazar, 2014: 78).

Con esta detallada información se puede rastrear un panorama más amplio de los alimentos, así como de su procedencia y el uso que se les daba según cada orden religiosa, brindando una reflexión más cercana al mundo de lo culinario dentro de los espacios monacales.

Como se puede ver, el estudio relacionado con la cocina conventual comienza a aportarnos otras interpretaciones de las prácticas alimentarias y del contexto 
en el cual se ubicaban, vinculando lo culinario no sólo con el tema de la cocina sino más allá, siendo un aspecto que se liga directamente con el ámbito de lo económico, lo social y, sin lugar a dudas, dentro del referente de lo cultural.

\section{REFLEXIÓN FINAL}

Gracias a la revisión que se presentó en este artículo es posible distinguir dos momentos en la historiografía sobre la alimentación conventual. Por un lado están los trabajos que hacen énfasis en factores que han marcado a la cocina monacal: los fuertes ayunos con la finalidad de obtener la pureza y santidad, y la producción de dulces conventuales.

Por otro lado, los recientes estudios brindan un contexto de cómo se fueron desarrollando los hábitos alimentarios dentro de estos centros de una manera más apegada a la cotidianeidad y la continuidad de las prácticas a través de la historia.

Una forma de lograrlo es considerar la arquitectura y la propia organización de la comunidad, y con ello reconocer cómo y en dónde se llevaba a cabo el proceso de lo culinario. Otra alternativa es reinterpretar las Reglas y las Constituciones de las órdenes religiosas con el propósito de conocer el tipo de alimentos que se incluyeron en cada dieta, hecho que brinda un contexto amplio sobre los productos que conformaron, a partir de gustos y limitantes, la cocina novohispana. Por último, repensar la forma en que se obtenían los alimentos, como por ejemplo, pagos en especie de las dotes y las rentas de las monjas; esta nueva perspectiva abre la posibilidad de desarrollar investigaciones centradas en el papel que jugó la cocina conventual en los propios centros y su impacto en la sociedad novohispana.

Considerar estas interpretaciones permite ampliar la visión del tema de la alimentación. Si bien, es de interés relevante considerar la creación de los platillos que surgieron durante la época novohispana, es más rico aún el análisis desde los diferentes ámbitos en los que la comida juega un papel en el desarrollo y el impacto de lo culinario, un ámbito que no se queda en la obtención de ingredientes y utensilios, sino que muestra un gran número de relaciones concatenadas entre lo conventual y el mundo exterior. 
REFERENCIAS

AmerLinCK, M. (1995). Conventos de monjas: fundaciones en el México virreinal. México: Grupo Condumex.

ARIAS, J. (2007). Los místicos sabores del convento. Las monjas Clarisas Urbanistas y sus hábitos alimenticios en Querétaro siglos XVII-XVIII. México: Consejo del IV Centenario de la fundación del Convento de Santa Clara de Jesús.

BAZARTE, A. (2006). Un acercamiento a la comida novohispana. México, IPN.

CAStelló, T. (2000). El libro de cocina del hermano fray Gerónimo de San Pelayo. México: CONACULTA.

CASTELLó, T. (2000). Delicias de antaño: historia y recetas de los conventos mexicanos. México: Océano.

GarcíA, D. (2007). El accidente de epilepsia en el convento de religiosas del glorioso y máximo doctor señor san Jerónimo en la Puebla de los Ángeles, en Desde el claustro de la higuera. Objetos sacros y vida cotidiana en el ex convento jerónimo de San Lorenzo. México: IPN, pp. 158-172.

Laviín, A. (2016). Las esposas de Cristo. La vida conventual en la Nueva España, México: Fondo de Cultura Económica.

LoRETo, R. (2000). Los conventos femeninos y el mundo urbano de la Puebla de los Ángeles del siglo XVIII. México: El Colegio de México.

Muriel, J. y Pérez, G. (1996). Los hallazgos gastronómicos: bibliografía de cocina en la Nueva España y el México del siglo XIX. Conquista y comida. Consecuencias del encuentro de dos mundos. México: UNAM.

MuRIEL, J. (1982). Cultura femenina novohispana. México: UNAM.

Muriel, J. (1946). Conventos de monjas en la Nueva España. México: Ediciones Santiago.

Pérez, L. (2005). Autos de las vivistas del Arzobispo fray Payo Enríquez a los conventos de monjas de la ciudad de México (1672-1675) México: UNAM-CESU.

REYNA, M. (1990). El convento de San Jerónimo: vida conventualy finanzas. México: INAH. SALAZAR, N. (2014). Ingredientes para la cocina conventual: producción y compras en dos estudios de caso. Boletín de Monumentos Históricos (30) México: INAH, pp. 72-93.

SERIE

(2000). Cocina virreinal novohispana. México: Clío. 
